\section{San Esteban de Atán (Lugo). Un ejemplo de iglesia que no es lo que parece}

Luis Caballero, Fernando ArCe, M. a de los Ángeles Utrero Unidad Asociada CSIC/Universidad del País Vasco. Grupo de Arqueología Tardoantigua y Medieval. Arqueología de la Arquitectura (GATMAA)

\section{Resumen}

El análisis arqueológico de la iglesia de San Esteban de Atán (Lugo) ofrece una secuencia estratigráfica rica en fases y resultados. Las fuentes documentales y algunos elementos decorativos (celosías) parecían afirmar la existencia de una iglesia prerrománica anterior a la actual de época románica. La lectura de paramentos no documenta ninguna fase constructiva que pueda corresponder a estos indicios. De las piezas singulares consideradas como prerrománicas, sólo una puede confirmarse de esta fecha, pero desconocemos su emplazamiento original. Sobre esta base, no se puede sostener la hipotética iglesia prerrománica. En segundo lugar, la construcción actual, catalogada en época románica de acuerdo a las tipologías arquitectónicas y decorativas, pertenece en realidad a época bajomedieval, como demuestran diversas relaciones y el hecho de que los elementos aceptados como indicadores cronológicos se hallan reutilizado en los muros. Los resultados de Atán plantean cuestiones de clasificación dentro de la Historia del Arte, donde el ejemplo estudiado seguro que no es una excepción.

Palabras clave: San Esteban de Atán; análisis estratigráfico; arquitectura prerrománica; arquitectura bajomedieval; reutilización.

\begin{abstract}
The archaeological analysis of the church of San Esteban de Atán (Lugo) offers a stratigraphic sequence rich in phases and results. Documentary sources and some decorative elements (lattices) appear to affirm the existence of a pre-Romanesque church previous to the present Romanesque style church. The reading of facings does not document any building phase that might correspond to these indications. Of the singular pieces considered pre-Romanesque, only one can be confirmed from this date, but its original location is unknown. On this basis, it is impossible to sustain the hypothesis of the church as pre-Romanesque. Secondly, the present construction, catalogued as belonging to the Romanesque period according to architectonic and decorative typologies, belongs in fact to the low medieval period, as seen in diverse relations and in the fact that elements accepted as chronological indicators have been reused in the walls. The results at Atán challenge the classifications within history of art, and this example is surely not an exception.
\end{abstract}

Key words: San Esteban de Atán; stratigraphic analysis; preRomanesque architecture; low medieval architecture; reuse.

\section{PROPUESTA:BUSCAR UNA IGLESIA PRERROMÁNICA}

La lectura de paramentos de la iglesia de San Esteban de Atán (Pantón, Lugo) se planteó como instrumento para definir los elementos pertenecientes a las etapas más antiguas, en concreto una etapa prerrománica, cuya posible existencia derivaba de dos indicios: por un lado, de la presencia de tres celosías consideradas de época prerrománica (NúÑEZ, 1978; CHAmoso y otros, 1980), reutilizadas en la parte superior del muro este de la nave y en los muros este y sur de la casa parroquial (Fig. 3); por otro, de las referencias documentales escritas que afirmaban la existencia de un monasterio del siglo VIII sustituido por una iglesia prerrománica en el año 871 (VÁzquez de Parga, 1950; Castillo, 1972). La interpretación tradicional concluía, a partir de esta información, que la actual iglesia románica se alzaba sobre una anterior prerrománica. Por este motivo, como labor previa a la intervención restauradora, se nos solicitó la identificación de los restos de la iglesia altomedieval para evitar su destrucción y resaltarlos con la restauración.

La iglesia actual de San Esteban de Atán es de una única nave con cubierta de madera y presbiterio rectangular con bóveda de cañón en sillería. Posee dos accesos, una portada principal en la fachada y otra menor no centrada en el muro norte. En su lado sudoeste se sitúa una torre de planta cuadrada y la casa parroquial ocupa todo el lado sur de la iglesia. Delante de la fachada oeste se localiza el cementerio actual.

\section{ANTECEDENTES}

El trabajo se inició con el conocimiento previo de los informes arqueológicos e históricos proporcionados por la Xunta de Galicia. Las referencias bibliográficas fueron ampliadas por el equipo de trabajo.

La excavación arqueológica (Bonilla, 1998) documentó varios niveles de enterramientos, uno del siglo XIX y otro de época moderna, y un tercero, roto por los anteriores, asociado al denominado nivel románico de cimentaciones de la iglesia, el cual se descubrió tanto en la nave como en el presbiterio. Finalmente, se llegó al nivel de cimentaciones de una estructura que ocuparía el último tercio de la nave por su lado oeste y continuaría hacia el exterior. Su datación prerrománica se basa, según los arqueólogos, en su anterioridad a las tumbas románicas y en su relación con la torre, la cual se considera también prerrománica. Estas estructuras y las supuestas celosías responderían al momento prerrománico citado en las referencias escritas. Consecuentemente, la iglesia actual de época románica se situaría sobre dicho conjunto prerrománico.

El informe histórico artístico (FONTELA Y BARRAL, 1996) se centraba, entre otros, en el estudio de los docu- 
mentos referentes a los siglos IX-X y XII, donde se habla de Atán como un monasterio con iglesias y villas dependientes, y del Libro de Fábrica de la iglesia del siglo XVIII, depositado en el Archivo Histórico Diocesano de Lugo, en el que se recogen las obras y restauraciones realizadas desde principios del XVIII hasta 1899. En este informe, ya se indica que algunos capiteles y modillones aparentemente románicos deberían ser en realidad de un momento más tardío.

\section{SECUENCIA ESTRATIGRÁFICA}

El estado de conservación actual de la iglesia y la última restauración, realizada de manera urgente para evitar su caí$\mathrm{da}$, condicionaron en gran medida la lectura del edificio (Fig. 2). El enfoscado y enlucido por completo del interior de la iglesia, los apuntalamientos de madera de los dos arcos fajones de la bóveda del presbiterio y del arco de entrada a éste y los apuntalamientos metálicos exteriores de las cuatro fachadas, así como una solera de hormigón que se extendía por toda la nave y el ábside, sellando la excavación arqueológica, dificultaron el proceso de individualización de las unidades estratigráficas. La secuencia obtenida puede resumirse de la siguiente manera (Fig. 1).

Etapa I. Alto Medieval o Prerrománica. La lectura no ha documentado la existencia de ningún resto prerrománico en alzado. Esta etapa se reservó para las posibles estructuras prerrománicas aparecidas en la excavación arqueológica, previa a nuestra labor y tapada por una solera de hormigón, y otras consideradas por ésta pertenecientes a época prerrománica, como la torre y los restos decorativos (modillón reutilizado en los cimientos). Estos aspectos se discuten en el resumen de la secuencia estratigráfica.

Etapa II. Plena Edad Media. Torre exenta y primer edificio Norte (A101 y 102). Las partes bajas del muro norte y de la torre, entonces exenta, son los primeros restos arquitectónicos documentados en la iglesia, pero no pertenecen al edificio actual, sino a otros de cronología plenomedieval y de distinta distribución. Excavación y lectura coinciden en
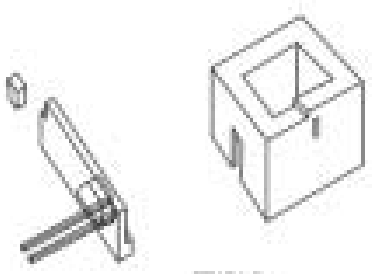

ETwan:
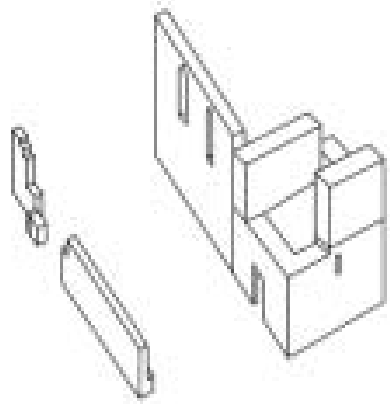

ตT⿻上丨)
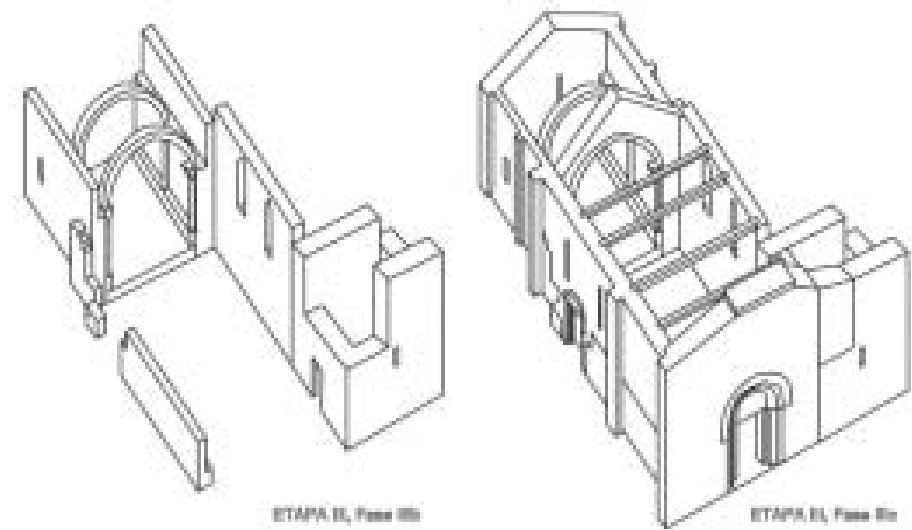

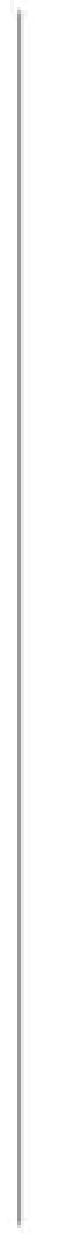

Fig. 1. Evolución de la iglesia en alzado y en planta. 


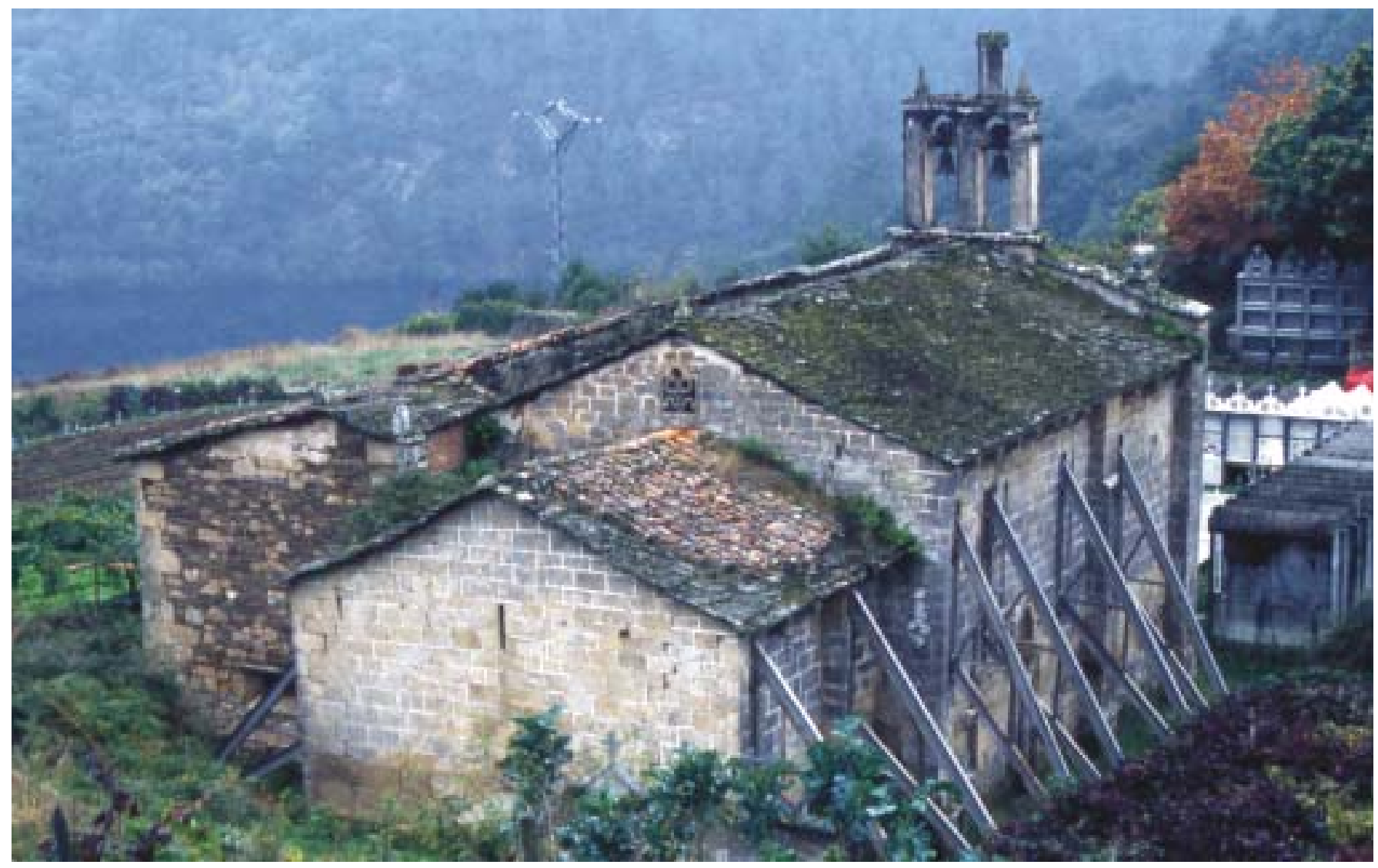

Fig. 2. Ábside y cuerpo de la iglesia desde el Noreste

que el edificio se extiende fuera de la actual iglesia, hacia el Norte, y que estaba relacionado con la torre.

La parte inferior del muro norte (A102) y la parte original de la torre (A101) poseen un aparejo distinto, en el primer caso construido en sillería reutilizada y en el segundo en mampostería con encadenados de sillería en las esquinas y puerta, de la que sólo pertenecen a la primera época las nacelas, el salmer y la primera dovela del lado oeste. Las diferencias de fábrica pueden atribuirse a cronologías distintas o a funciones constructivas diferentes.

La reutilización de sillería remite a una ruina y desmonte de edificios anteriores, bien del mismo lugar, bien de las proximidades. Una fila de mechinales marca el límite superior en el exterior de la A102, lo que hace referencia a la existencia de un edificio que se extendía hacia el Norte y que poseía o un forjado para un segundo piso o una cubierta, siendo más probable lo primero. Un arcosolio se ubica en la parte inferior de la cara sur de la A102; sus hiladas inferiores indican que es contemporáneo al muro, no así las superiores, que presentan un ligero quiebro, retalle de las caras de los sillares y una clave descentrada, argumentos para considerarlas de una actividad posterior. El arcosolio, tanto si lo considerásemos interior como exterior del edificio original, podría hacer pensar en una iglesia u otro posible edificio con un nicho sin función funeraria.

El límite cronológico establecido para la A102 plantea también el problema de la procedencia y el origen de ciertos elementos. Las dos portadas románicas y los modillones no se incluyen estratigráficamente en dicha actividad, a lo que podemos dar tres explicaciones: podrían proceder de un lugar cercano, lo que ubicaría una iglesia primitiva en otro punto; podrían pertenecer al propio edificio A102, lo que avalaría la existencia de una iglesia; o corresponder a la A106, restauración de la A102 (fase IIIa), perteneciente a un edifico eclesial románico.

La torre (A101) pertenecería a una etapa románica y el resto del muro norte del aula (A102) sería coetáneo o posterior, si se acepta la tipología gótica del arcosolio.

Por último, el escalón de la embocadura del ábside (A103) permanece como elemento aislado dentro de esta etapa. La estratigrafía no permite concretar sus relaciones con otras unidades: podría pertenecer a esta etapa o a la inmediatamente posterior, por lo que se ha situado en un periodo II/IIIa.

Etapa III. Tardo Medieval y Moderna. Construcción de la iglesia actual. En este momento, se configura el actual edifi- 
cio, aprovechando los restos de la etapa anterior y construyendo la fachada y el ábside. Los elementos decorativos y su ritmo de disposición indican que se trasladaron desde otro lugar para reutilizarlos en los muros del ábside y del aula (modillones, cornisas, basas de columnas) y para remontar las portadas (dovelas y columnas). Como faltaban elementos para completar estas estructuras, se tallaron nuevos capiteles y modillones, imitación torpe de los reutilizados.

Fase IIIa. Época Gótica. Primeros restos de una iglesia (A104/106). La torre y el muro norte sufren una primera restauración y se construye el muro meridional de la iglesia.

La restauración interior de la torre (A104) rehace el arco de la puerta y continúa el muro de mampostería. Se plantea aquí la misma duda que en la etapa II respecto a la relación de la torre y del muro norte por su diferencia de fábrica. En este caso, el muro meridional y la restauración de la torre se consideran de un mismo momento, por lo que deberían haber sido construidos ambos en sillería, y, sin embargo, la torre se restaura de nuevo con mampostería. Se puede pensar también en una fase intermedia de restauración de la torre, anterior a la construcción del muro sur. Por otro lado, el muro este de la torre (A101) y el muro sur de la nave se cortan y adosan alternativamente, lo que tampoco ayuda a clarificar una secuencia constructiva de ambos muros.

El muro meridional (A105) se construye entero en esta etapa en sillería reutilizada a hueso, calzada y con dos escalones horizontales y cimientos de lajas de pizarra. Algunos sillares presentan marcas de cantero y grafías, en una de ellas se puede leer «10 otubre», pero no se puede apreciar por su posición en alto, si pertenece a un momento coetáneo o posterior. Dos ventanas asaetadas en mitra indican una posible cronología gótica. La imposibilidad de ver este muro al interior por la presencia del encalado, como ocurre con el muro norte, limita la definición de otras posibles etapas.

Por último, la restauración oriental de A102 (A106) es coetánea al muro frontero meridional, realizada en sillería de peor talla y con diferente tamaño y forma de los escalones inferiores de biselado irregular.

Fase IIIb. Cabecera de la iglesia actual (A108/110). En este momento se añade el ábside (A108) de testero plano y dos tramos abovedados separados por arcos fajones sobre columnas adosadas con sotabanco corrido y ventanas asaetadas. Se construye en sillería reutilizada asentada con pizarra, con dos escalones bajos que continúan los anteriores (A 105 y 106). La tipología de ventanas asaetadas, la imposta interior interrumpida ante las dovelas de estas, la irregularidad de las molduras de las basas de las columnas y el ritmo

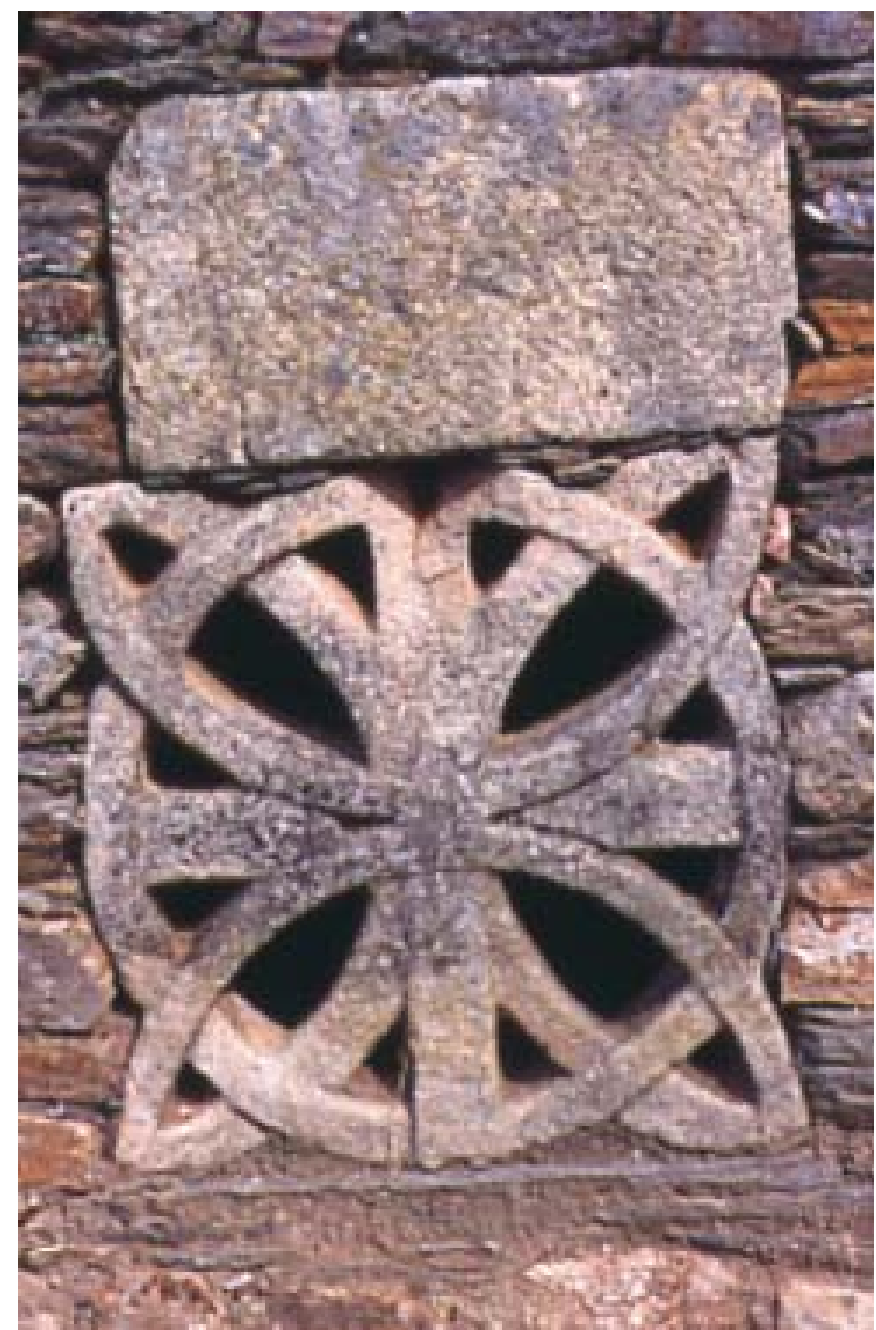

Fig. 3. Pieza reutilizada en el muro sur de la casa parroquial.

y motivos de los modillones y cornisas indican la reutilización de estos elementos en la construcción del ábside desde un principio. Los cimientos (A110) de la nave también presentan un corte en la embocadura del ábside.

$\mathrm{El}$ interior del muro norte presenta pinturas de carácter gótico, cubiertas por el enfoscado, lo que dificulta de nuevo el reconocimiento de los límites de A106 y la diferenciación de la posterior A111.

Fase IIIc. Construcción de la iglesia actual. Fachada, portadas y refuerzo del edificio (A111/114). Se construyen los tres testeros, los del aula (A111), es decir, el cierre sobre el arco de triunfo y la fachada oeste, y el del ábside (A113). $\mathrm{Su}$ fábrica es similar y se rematan con contrafuertes que cortan y se adosan a los muros norte y sur de la nave y presbiterio, presentando ambos elementos, muro y contrafuerte, un cimiento unitario. La fachada oeste se enjarja con la torre en su lado sur, mediante el remontado de los sillares.

Las piezas de las dos portadas están movidas, lo que indica que éstas han sido montadas de nuevo utilizando 


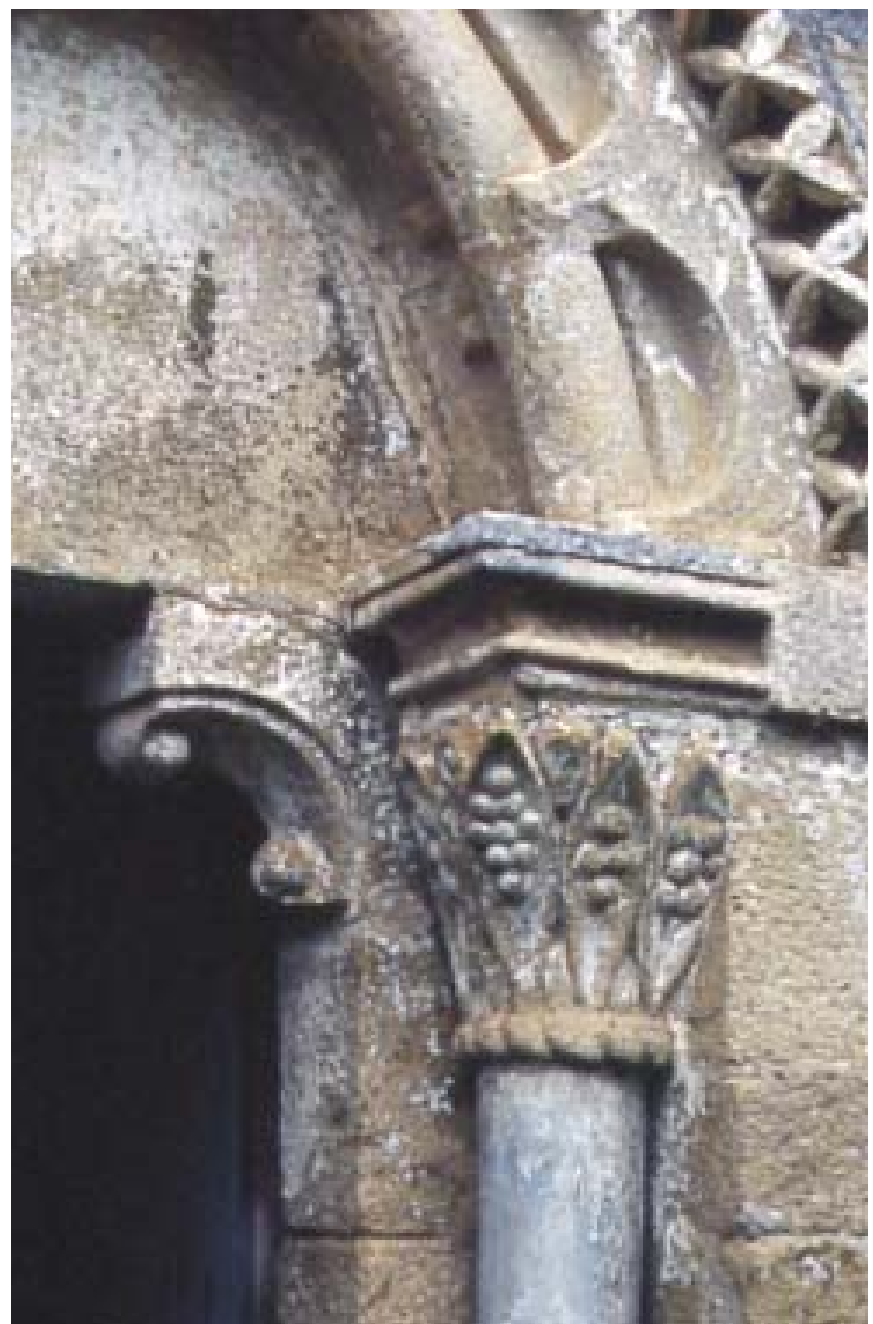

Fig. 4. Capiteles de la jamba oeste de la puerta norte.

elementos antiguos y tallando otros nuevos a modo de copia (Fig. 4). Son nuevos, por ejemplo, los modillones que rematan los muros del aula, a imitación de los del ábside. Representan la finalización de la obra, anterior a la documentación del Libro de Fábrica, lo que puede llevarnos a una cronología del XV-XVII.

Etapa IV. Siglo XVIII. Retablo, pintura y pequeñas reformas (A120/125). En el retablo de tipología barroca reza una inscripción, referente a su pintura, del año 1796. Documentadas en el Libro de Fábrica, encontramos las siguientes actividades: cierre del arcosolio (A120) y de la ventana del ábside (A121) en 1736; reforma de la ventana meridional del ábside (A124) con la vidriera, marco de hierro y red de alambre en 1766. En ambos momentos, también se documentan el tratamiento de las superficies, en 1736 el encalado de los muros y rejuntado de la sillería, y en 1766 el revocado, encalado y encintado de los muros (A122 y A125).
Etapa V-VII. Siglos XIX-XX. Sacristía, casa parroquial, desmoche de la torre (A139/150) y cementerio, espadaña e intervención restauradora (A151/155). La torre sirvió como campanario hasta finales del XVIII, hecho conocido por la documentación conocida de las sucesivas restauraciones que sufre dado su mal estado. Su desmoche se da, estratigráficamente, con la construcción de la casa parroquial en la segunda mitad del XIX.

La primera sacristía se documenta en 1791, cuando se ordena su construcción en el lado meridional y la apertura de la puerta en el presbiterio. La sacristía se encontraba separada de la torre pues, a principios del XIX, se ordena construir una caseta entre la torre y el presbiterio, momento en el que se hace referencia a la apertura de las puertas. A mediados del XIX, se construye la actual casa parroquial (A146), de dos pisos, como indican los mechinales del muro meridional del aula y el muro oriental de la torre. Ocupa todo el lado sur de la nave y reutiliza los modillones románicos y modernos de ésta, desmontados al elevar el muro de la nave para apoyar la cubierta del nuevo edificio, así como dos celosías (Fig. 3).

En época contemporánea (Etapa VI), se monta la espadaña (A153) de ladrillo revocado en cemento en el remate del frontón de la fachada, lo que obligó a trasladar el Agnus Dei al extremo norte (A154; Fig. 2). Por la misma época, se crea el cementerio actual delante de la fachada occidental, incluso se coloca una lápida en ella y otra en la torre, con fechas de 1951 y 1956 (A152).

Por último, la Etapa VII engloba las últimas restauraciones (A155), la solera de hormigón del interior de la iglesia, los cortes de la excavación y el movimiento de tierras.

\section{RESULTADO: SE ENCUENTRA LA IGLESIA MODERNA DE ATÁN}

La secuencia estratigráfica transforma radicalmente la visión de la iglesia. No existe ningún resto de la iglesia prerrománica citada en los textos; los primeros muros conservados son de plena época medieval y la disposición de la iglesia actual es de fines de la Edad Media e inicios de la Moderna.

Según la documentación histórica, la iglesia de San Esteban es la continuación de un monasterio de origen prerrománico fundado por el obispo Odoario en el 747 o 757 y refundado en el mismo siglo VIII (CASTILLO, 1972: n. ${ }^{\circ} 53$ ) o por el arcediano Damondo o Damundo en 954 (VÁZQuez SaCo, 1950: 115-116). Vázquez de Parga (1950) considera, sin embargo, estos documentos falsos, producto de los pleitos que mantenía la iglesia de Atán con la catedral de Lugo.

De acuerdo a esta documentación y a las características estilísticas, las celosías corresponderían al monasterio 
prerrománico. NÚÑEZ (1978) cita una cuarta celosía con dos arcos de herradura, como procedente de Atán, pudiéndose tratar de la referencia conocida de la existencia de una celosía en una casa de Atán, la cual desconocemos. Para RIVAS (1971), las celosías reutilizadas en la casa parroquial serían más bien remates del testero de probable cronología románica (Fig. 3), dando como más antigua la del testero oriental de la nave. Nuestro estudio concluye que dos de las tres supuestas celosías prerrománicas son en realidad cruces caladas, perfectamente documentadas y conocidas en la arquitectura románica de la zona, que se colocaban en las limas de los tejados, a menudo sobre los lomos de un cordero esculpido (Agnus Dei). Sólo la tercera pieza podría ser de una fecha altomedieval, pero ¡cuál es su procedencia? Por otro lado, la tipología de las piezas apunta a una cronología más avanzada, de finales del X y comienzos del XI.

Ni las noticias documentales referidas a los siglos VIII y IX, ni la posible celosía prerrománica tienen su refrendo en la secuencia estratigráfica: no se documenta una fase constructiva de fecha altomedieval. Si existieron edificios altomedievales en Atán, estarían en otro lugar.

Respecto a la tipología de la planta, encontramos paralelos muy cercanos en el entorno, lo que puede plantear una extensión de la problemática cronológica de construcción a estos edificios considerados románicos por su tipología de planta y sus elementos decorativos. Una rápida visión de la arquitectura de la región, con la alusión a reconstrucciones en varias de sus iglesias (YZQUIERDO, 1983, ejemplos como Sta. María de Bermún, S. Miguel de Oleiros o Salvador de Merlán, cuyos paramentos muestran irregularidades que de seguro tienen una traducción estratigráfica), hace pensar en posibles secuencias similares a las constatadas en Atán y dudar sobre su correcta adscripción. Quizás un análisis arqueológico descubriría más ejemplos catalogados en época románica resultado de actuaciones modernas.

La tradicional consideración románica de la iglesia, basada en elementos tipológicos como las portadas y la decoración, pierde su relevancia al constatarse la reutilización de todos ellos. Estas piezas pasan, por tanto, de ser indicadores cronológicos a ser elementos intrusivos. Son los elementos imitados los que datan la iglesia. La fecha del siglo XII viene dada por la puerta de la torre como elemento de datación y la parte baja del arcosolio, si consideramos la parte superior por su tipología apuntada de época gótica. El límite del siglo XIV para la fase III, cuando se construye la iglesia actual, debe tomarse con cautela dados los problemas de reutilización de los elementos decorativos románicos/pregóticos. Finalmente, se debe hacer referencia a la imposibilidad de reconocer más fases constructivas en los muros interiores del aula, que por ahora debemos basar solamente en las caras exteriores hasta que se proceda a una limpieza del interior.

\section{Ficha técnica}

Xunta de Galicia (Dirección Xeral de Patrimonio Cultural de la Consellería de Cultura y Comunicación Social) - CSIC (Instituto de Historia).

Arquitectos, J.R. Quiroga, V. L. Miguel Suárez. Excavación arqueológica, Andrés Bonilla. Informe Histórico, Concha Fontela.

Equipo, L. Caballero Zoreda (Director), F. Arce Sainz, M. ${ }^{a}$ A. Utrero Agudo. Octubre 1999.

\section{Fuentes documentales}

Archivo Diocesano y Central Parroquial de Lugo. Libro de Fábrica, 1.

\section{Bibliografía}

Azkarate A., Fernández de Jauregui A., NúÑez J., 1995, Documentación y análisis arquitectónico en el País Vasco. Algunas experiencias llevadas a cabo en Âlava - España, Leer el Documento Construido, Informes de la Construcción, 46, pp. 65-77.

Bonilla Rodríguez A., 1998, Trabajos arqueológicos en la iglesia de $S$. Estebo de Atán (Ferreira de Pantón, Lugo), Informe preliminar (manuscrito).

CAÑada S., 1974, Gran Enciclopedia Gallega (voz Atán, S. Estebo de y voz Pantón), T.III/5, pp. 253-255, Santiago de Compostela.

Chamoso Lamas M., González V., Regal D., 1980, Galicia Románica, Madrid.

Fontela San Juan C., Barral Rivadulla D., 1996, Iglesia parroquial de San Esteban de Atán (manuscrito).

NúNEZ M., 1978, Arquitectura Prerrománica, Historia de Arquitectura Galega, COAG, Madrid.

RIVAS FERNÁNDEZ J.C., 1971, Algunas consideraciones sobre el prerrománico gallego y sus arcos de herradura geminados, Boletín Auriense, 1, pp. 61-125.

Sá Bravo H., 1972, El monacato en Galicia, Madrid.

SAlgado Toimil R., 1922, Odoario, pp. 25-37, Lugo.

SÁNCHEZ BELDA L., 1953, Documentos reales de la Edad Media referentes a Galicia. Catálogo de los conservados en la Sección de Clero del Archivo Histórico Nacional, Catálogos de Archivos y Bibliotecas, Madrid.

VÁzQUeZ DE PARGA L., 1950, Los documentos sobre las presuras del obispo Odoario de Lugo, Hispania, X/XLI, pp. 635-680.

VÁzQUEZ SACO F., 1950, Papeleta 119. Iglesia parroquial de San Esteban de Atán, Boletin de la Comisión de Monumentos de Lugo, 4, pp. 115-119.

YZQUieRdo PeRRín R., 1983, La arquitectura románica en Lugo, La Coruña. 